\title{
Cell responses without receptors and ligands, using nanosecond pulsed electric fields (nsPEFs)
}

\author{
This article was published in the following Dove Press journal: \\ International Journal of Nanomedicine \\ 30 August 2013 \\ Number of times this article has been viewed
}

\author{
Stephen J Beebe \\ Frank Reidy Research Center for \\ Bioelectrics, Old Dominion University, \\ Norfolk, VA, USA
}

The plasma membrane is a lipid bilayer that surrounds and shelters the living structural and metabolic systems within cells. That membrane is replete with transmembrane proteins with and without ligand binding sites, oligosaccharides, and glycolipids on the cell exterior. Information transfer across this structure is closely controlled to maintain homeostasis and regulate cell responses to external stimuli. The plasma membrane is contiguous with the endoplasmic reticulum (ER) and nuclear membranes. A number of proteins form ER-mitochondria junctions, allowing interorganelle communications, especially for calcium transport. Transport mechanisms across these membranes include nongated channels or pores; single-gated channels for ion transport; carrier molecules for facilitated diffusion; and pumps for active transport of ions and macromolecules. During the activation of these transport systems, "pores" are formed through protein structures that transiently connect the intracellular and extracellular milieu. These pores are nanoscale structures with diameters of $0.2-4.0 \mathrm{~nm}$. However, there can also be maligned movements of molecules across the plasma membranes. Staphylococcus aureus protein $\alpha$-toxin and Streptococcus pyogenes protein streptolysin O both create pores that allow unsolicited molecular transfer across membranes that disrupts vital functions. Cytotoxic T-cells permeabilize the invading cell membranes with perforin, creating pores through which granzymes can induce apoptosis. These pores have a lumen of $5-30 \mathrm{~nm}$ with the majority at $13-20 \mathrm{~nm} .^{1}$

There are also nonbiological means to permeabilize plasma membranes that can be effective in delivery of drugs or nucleic acids into cells for basic biological or therapeutic purposes. In contrast to nature's permeabilization of plasma membranes through proteins, these nonbiological methods permeabilize the lipid bilayer itself. Some methods include sonoporation (high frequency ultrasound and microbubbles), laser- or optical-transfection, and electroporation using electric fields to create "pores" or aqueous channels (there are also a number of other transfection methods that do not necessarily form pores in cell membranes).

Over 30 years ago, electric fields were shown to transiently permeabilize plasma membranes and to introduce deoxyribonucleic acid (DNA) into cells by electroporation. ${ }^{2}$ A quarter of a century later, electroporation has been used in clinical trials with gene electrotherapy (GET) to deliver interleukin (IL)-12 to lesions in melanoma patients, showing safety and efficacy. ${ }^{3}$ Another use of electroporation is to deliver impermeant cancer drugs, such as bleomycin, to tumors by electrochemotherapy (ECT). ${ }^{4,5}$ Clinical applications for ECT have been demonstrated, ${ }^{6}$ and ECT is now practiced clinically in
Correspondence: Stephen J Beebe Frank Reidy Research Center for Bioelectrics, Old Dominion University, Norfolk, VA, USA

Tel +l 7576832405

Fax + I 75745 I 1010

Email sbeebe@odu.edu 
several European Union countries. ${ }^{7}$ Another method of cancer treatment using electric fields is to irrevocably permeabilize tumor cells by irreversible electroporation (IRE). ${ }^{8}$ While GET, ECT, and IRE all use pulse durations in micro- to millisecond ranges, GET and ECT use electric fields of a few hundred V/cm; in contrast, IRE uses increased electric fields, up to $3 \mathrm{kV} / \mathrm{cm}$. This creates cell permeabilization conditions that are irreversible, and cells are ablated and die, primarily by necrosis.

Another new electric field application in basic biology and medicine is pulsed power technology, which has been used for decades for military applications and pulsed power physics. ${ }^{9,10}$ This approach makes greater use of high-voltage capacitors with fast discharge capabilities. These devices compress and immediately release high-power electrical pulses of extremely short duration into cells or tissues. In contrast to GET, ECT, and IRE, pulsed power delivers pulses of nanosecond duration, with higher intensity electric fields. These high power, low energy, nonthermal pulses are called nanosecond pulsed electric fields (nsPEFs) or nanoelectropulses. The pulses that are used have durations of 4-600 ns and electric fields of up to $60-80 \mathrm{kV} / \mathrm{cm}$; however, electric fields as high as $300 \mathrm{kV} / \mathrm{cm}$ have been used, with pulse durations of $10 \mathrm{~ns}$. By exploiting the variables of cell/tissue type and nsPEF conditions (pulse number, duration, intensity, and repetition rate), a range of biological responses can be observed. There is evidence that nsPEF-induced cell responses are different from the responses to electroporation. ${ }^{10-12}$

In contrast to conventional electroporation, under certain conditions, nsPEFs create small, propidium iodide (PI)-impermeable pores in plasma membranes and intracellular organelles, called nanopores. ${ }^{13,14}$ The formation of high-density nanopores in all cell membranes is referred to as supraelectroporation. ${ }^{15,16}$ These plasma membrane nanopores are long lasting (minutes) and exhibit complex ion channel-like conductance that is voltage-sensitive and inwardly rectifying. When these pores become PI-permeable, like conventional electroporation pores, they become highly conductive and nonrectifying. These nanopores are hypothesized to induce many nsPEF effects. . $^{14,16,17}$

NsPEF effects occur in the absence of ligands or receptors. NsPEFs have been shown to breach intracellular granules, ${ }^{9}$ to mobilize $\mathrm{Ca}^{2+}$ from the ER and through plasma membranes, ${ }^{18-20}$ and to modulate intracellular $\mathrm{Ca}^{2+}$ levels in chromaffin cells, mostly or exclusively through nanopores in the plasma membranes. ${ }^{21}$ The mobilization of $\mathrm{Ca}^{2+}$ induces secondary responses to nsPEFs and manipulates selected responses to changes in the intracellular $\mathrm{Ca}^{2+}$. In human neutrophils, nsPEFs suppress spontaneous $\mathrm{H}_{2} \mathrm{O}_{2}$ production and reversibly attenuate chemotaxis but do not affect phagocytosis, the least sophisticated neutrophil activity of the three functions. ${ }^{22}$ The nsPEF-induced mobilization of $\mathrm{Ca}^{2+}$ also activates human platelets-forming platelet gels, ${ }^{23}$ induces action potentials in cardiomyocytes, ${ }^{24}$ activates mitogen-activated protein kinase (MAP) ${ }^{25}$ and adenosine monophosphate (AMP) ${ }^{26}$ kinases, and induces a novel stress response. ${ }^{27} \mathrm{NsPEFs}$ induce calcium-dependent reactive oxygen species, which appear to require calcium entry through the plasma membrane pores. ${ }^{28}$ Most recently, it has been shown that pulses of $10 \mathrm{~ns}$ duration can induce the plasma membrane permeabilization of giant unilamellar vesicles to small interfering ribonucleic acid (siRNA) ${ }^{29}$ This provides yet another potential means to elicit cell responses without reliance on receptors and ligands.

NsPEFs also cause a rapid time- and electric field-dependent dissipation of the mitochondria membrane potential $(\Delta \Psi \mathrm{m}) .^{30-32}$ Interestingly, loss of $\Delta \Psi \mathrm{m}$ requires an influx of $\mathrm{Ca}^{2+}$ through the plasma membranes, which is necessary, but not sufficient to dissipate $\Delta \Psi \mathrm{m}$ and induce cell death. ${ }^{11,33}$ Since plasma membrane permeabilization is not $\mathrm{Ca}^{2+}$-dependent, ${ }^{17} \mathrm{nsPEF}$-induced loss of $\Delta \Psi \mathrm{m}$ is not likely due to nanopore formation in the inner mitochondria membranes, which would be expected based on the supraelectroporation hypothesis. Since most, if not all $\mathrm{Ca}^{2+}$-mediated mechanisms are regulated by proteins, the hypothesis that nsPEF effects are solely determined by membrane-charging events may require reconsideration. Given the close relationship between $\mathrm{Ca}^{2+}$-dependent losses of $\Delta \Psi \mathrm{m}$ and viability, ${ }^{11,33}$ it is likely that these events lead to mitochondria-mediated, intrinsic, caspase-dependent and -independent cell death, which has been observed in Jurkat cells. ${ }^{34}$

Other studies suggest that not all nsPEF effects are mediated by cell membrane nanopores. It has been shown that nsPEFs inhibit voltage-gated $\mathrm{Na}+$ and $\mathrm{Ca}^{2+}$ channels, ${ }^{35}$ and induce cytoskeletal breakdown and nuclear membrane abnormalities. ${ }^{36}$ By unknown mechanisms, nsPEFs also increase the substructures of small nuclear ribonucleoprotein particles or intrachromatin granule clusters, suggesting the modification of pre-messenger RNA-splicing mechanisms. ${ }^{37}$ However, it should be considered that some nsPEF effects are secondary to or require plasma membrane pore formation. NsPEF effects can be considered "supranatural." Living beings are electric in nature, composed of cell and tissue batteries in muscles, nerves, and other tissues. The application of additional charges from nsPEFs to intracellular structures and plasma membranes certainly transcends the natural. Since 
nsPEFs do no occur in nature, living organisms have not been under evolutionary pressure to develop responses to this stimulus. As expected, the responses to nsPEFs are distinct from those induced by previously known forms of cellular stresses. ${ }^{27}$ In this context, the author's laboratory has focused on cell death mechanisms as a means to eliminate cancers. This role has been recently reviewed for nsPEFs, as an alternative or adjunct for surgical removable of cancer. ${ }^{12}$ Any one or more of the nsPEF-induced cell responses presented above could directly or indirectly contribute to cell death. What seems clear is that when used at low repetition rates $(1-2 \mathrm{~Hz})$, nsPEF-induced cell death is not thermal nor immediate, but somewhat calculated and finally, default-driven. The research landscape that has most recently and surprisingly emerged and that is the focus of our present work, is the presence of a vaccine effect ${ }^{38}$ and possible immune response ${ }^{39}$ that materialize during/after nsPEF-induced tumor cell death.

\section{Disclosure}

The author reports no conflicts of interest in this work.

\section{References}

1. Law RH, Lukoyanova N, Voskoboinik I, et al. The structural basis for membrane binding and pore formation by lymphocyte perforin. Nature. 2010;468(7322):447-451.

2. Neumann E, Schaefer-Ridder M, Wang Y, Hofschneider PH. Gene transfer into mouse lyoma cells by electroporation in high electric fields. EMBO J. 1982;1(7):841-845.

3. Daud AI, DeConti RC, Andrews S, et al. Phase I trial of interleukin-12 plasmid electroporation in patients with metastatic melanoma. $J$ Clin Oncol. 2008;26(36):5896-5903.

4. Mir LM, Orlowski S, Belehradek J, Paoletti C. Electrochemotherapy potentiation of antitumour effect of bleomycin by local electric pulses. Eur J Cancer. 1991;27(1):68-72.

5. Sersa G, Cemazar M, Miklavcic D. Antitumor effectiveness of electrochemotherapy with cis-diamminedichloroplatinum(II) in mice. Cancer Res. 1995;55(15):3450-3455.

6. Heller R, Gilbert R, Jaroszeski MJ. Clinical applications of electrochemotherapy. Adv Drug Deliv Rev. 1999;35(1):119-129.

7. Miklavcic D, Snoj M, Zupanic A, et al. Towards treatment planning and treatment of deep-seated solid tumors by electrochemotherapy. Biomed Eng Online. 2010;9:10.

8. Davalos R, Mir IL, Rubinsky B. Tissue ablation with irreversible electroporation. Ann Biomed Eng. 2005;33(2):223-231.

9. Schoenbach KH, Beebe SJ, Buescher ES. Intracellular effect of ultrashort electrical pulses. Bioelectromagnetics. 2001;22(6):440-448.

10. Beebe SJ. Bioelectrics in basic science and medicine: impact of electric fields on cellular structures and functions. J Nanomed Nanotechnol. 2013;4(2):163.

11. Beebe SJ, Sain NM, Ren W. Induction of cell death mechanisms and apoptosis by nanosecond pulsed electric fields (nsPEFs). Cells. 2013;2(1):136-162.

12. Chen R, Chen X, Beebe SJ. Nanosecond pulsed electric field (nsPEF) ablation as an alternative or adjunct to surgery for treatment of cancer. Surgery Curr Res. 2013;S12:005.

13. Vernier PT, Sun Y, Gundersen MA. Nanoelectropulse-driven membrane perturbation and small molecule permeabilization. BMC Cell Biol. 2006;7:37.
14. Pakhomov AG, Bowman AM, Ibey BL, Andre FM, Pakhomova ON, Schoenbach KH. Lipid nanopores can form a stable, ion channel-like conduction pathway in cell membrane. Biochem Biophys Res Commun. 2009;385(2):181-186.

15. Stewart DA, Gowrishankar TR, Weaver JC. Transport lattice approach to describing electroporation: use of local asymptotic model. IEEE Trans Plasma Sci. 2004;32(4):1696-1708.

16. Gowrishankar TR, Esser AT, Vasilkoski Z, Smith KC, Weaver JC. Microdosimetry for conventional and supra-electroporation in cells with organelles. Biochem Biophys Res Commun. 2006;341(4): 1266-1276.

17. Pakhomov AG, Kolb JF, White JA, Joshi RP, Xiao S, Schoenbach KH. Long-lasting plasma membrane permeabilization in mammalian cells by nanosecond pulsed electric field (nsPEF). Bioelectromagnetics. 2007;28(8):655-663.

18. Vernier PT, Sun Y, Marcu L, Salemi S, Craft CM, Gundersen MA. Calcium bursts induced by nanosecond electric pulses. Biochem Biophys Res Commun. 2003;310(2):286-295.

19. White JA, Blackmore PF, Schoenbach KH, Beebe SJ. Stimulation of capacitative calcium entry in HL-60 cells by nanosecond pulsed electric fields. J Biol Chem. 2004;279(22):22964-22972.

20. Semenov I, Xiao S, Pakhomov AG. Primary pathways of intracellular $\mathrm{Ca}(2+)$ mobilization by nanosecond pulsed electric field. Biochim Biophys Acta. 2013;1828(3):981-989.

21. Craviso GL, Choe S, Chatterjee I, Vernier PT. Modulation of intracellular $\mathrm{Ca} 2+$ levels in chromaffin cells by nanoelectropulses. Bioelectrochemistry. 2012;87:244-252.

22. Buescher ES, Smith RR, Schoenbach KH. Submicrosecond intense pulsed electric field effects on intracellular free calcium: mechanisms and effects. IEEE Trans Plasma Sci. 2004;32(4):1563-1572.

23. Zhang J, Blackmore PF, Hargrave BY, Xiao S, Beebe SJ, Schoenbach KH. Nanosecond pulse electric field (nanopulse): a novel non-ligand agonist for platelet activation. Arch Biochem Biophys. 2008;471(2):240-248.

24. Wang S, Chen J, Chen MT, Vernier PT, Gundersen MA, Valderrábano M. Cardiac myocyte excitation by ultrashort high-field pulses. Biophys $J$. 2009;96(4):1640-1648.

25. Morotomi-Yano K, Akiyama H, Yano K. Nanosecond pulsed electric fields activate MAPK pathways in human cells. Arch Biochem Biophys. 2011;515(1-2):99-106.

26. Morotomi-Yano K, Akiyama H, Yano K. Nanosecond pulsed electric fields activate AMP-activated protein kinase: implications for calcium-mediated activation of cellular signaling. Biochem Biophys Res Commun. 2012;428(3):371-375.

27. Morotomi-Yano K, Oyadomari S, Akiyama H, Yano K. Nanosecond pulsed electric fields act as a novel cellular stress that induces translational suppression accompanied by eIF $2 \alpha$ phosphorylation and 4E-BP1 dephosphorylation. Exp Cell Res. 2012;318(14):1733-1744.

28. Nuccitelli R, Lui K, Kreis M, Athos B, Nuccitelli P. Nanosecond pulsed electric field stimulation of reactive oxygen species in human pancreatic cancer cells is $\mathrm{Ca}(2+)$-dependent. Biochem Biophys Res Commun. 2013;435(4):580-585.

29. Breton M, Delemotte L, Silve A, Mir LM, Tarek M. Transport of siRNA through lipid membranes driven by nanosecond electric pulses: an experimental and computational study. JAm Chem Soc. 2012;134(34): 13938-13941.

30. Ford WE, Ren W, Blackmore PF, Schoenbach KH, Beebe SJ. Nanosecond pulsed electric fields stimulate apoptosis without release of pro-apoptotic factors from mitochondria in B16f10 melanoma. Arch Biochem Biophys. 2010;497(1-2):82-89.

31. Ren W, Beebe SJ. An apoptosis targeted stimulus with nanosecond pulsed electric fields (nsPEFs) in E4 squamous cell carcinoma. Apoptosis. 2011;16(4):382-393.

32. Batista Napotnik T, Wu YH, Gundersen MA, Miklavčič D, Vernier PT. Nanosecond electric pulses cause mitochondrial membrane permeabilization in Jurkat cells. Bioelectromagnetics. 2012;33(3): $257-264$. 
33. Beebe SJ, Chen YJ, Sain NM, Schoenbach KH, Xiao S. Transient features in nanosecond pulsed electric fields differentially modulate mitochondria and viability. PLOS ONE. 2012;7(12):e51349.

34. Ren W, Sain NM, Beebe SJ. Nanosecond pulsed electric fields (nsPEFs) activate intrinsic caspase-dependent and caspaseindependent cell death in Jurkat cells. Biochem Biophys Res Commun. 2012;421(4):808-812.

35. Nesin V, Bowman AM, Xiao S, Pakhomov AG. Cell permeabilization and inhibition of voltage-gated $\mathrm{Ca}(2+)$ and $\mathrm{Na}(+)$ channel currents by nanosecond pulsed electric field. Bioelectromagnetics. 2012;33(5): 394-404.

36. Stacey M, Fox P, Buescher S, Kolb J. Nanosecond pulsed electric field induced cytoskeleton, nuclear membrane and telomere damage adversely impact cell survival. Bioelectrochemistry. 2011;82(2):131-134.
37. Chen N, Garner AL, Chen G, et al. Nanosecond electric pulses penetrate the nucleus and enhance speckle formation. Biochem Biophys Res Commun. 2007;364(2):220-225.

38. Beebe SJ, Ford WE, Ren W, Chen X. Pulse power ablation of melanoma with nanosecond pulsed electric fields. In: Morton R, editor. Treatment of Metastatic Melanoma. Zagreb: In Tech; 2011:231-268.

39. Nuccitelli R, Tran K, Lui K, et al. Non-thermal nanoelectroablation of UV-induced murine melanomas stimulates an immune response. Pigment Cell Melanoma Res. 2012;25(5):618-629.

\section{Publish your work in this journal}

The International Journal of Nanomedicine is an international, peerreviewed journal focusing on the application of nanotechnology in diagnostics, therapeutics, and drug delivery systems throughout the biomedical field. This journal is indexed on PubMed Central, MedLine, CAS, SciSearch $\AA$, Current Contents ${ }^{\circledR} /$ Clinical Medicine,
Journal Citation Reports/Science Edition, EMBase, Scopus and the Elsevier Bibliographic databases. The manuscript management system is completely online and includes a very quick and fair peer-review system, which is all easy to use. Visit http://www.dovepress.com/ testimonials.php to read real quotes from published authors. 